Brit. J. industr. Med., 1964, 21, 158

\title{
MEDICAL PROBLEMS OF WEARING A COALMINER'S SAFETY HELMET
}

\author{
BY \\ R. H. P. FERNANDEZ \\ From the East Midlands Division, National Coal Board
}

(RECEIVED FOR PUBLICATION SEPTEMBER 25, 1963)

\begin{abstract}
A survey of 324 men, who voluntarily reported an injury to that part of the head normally covered by a miner's safety helmet, took place at 18 collieries $(16,732 \mathrm{men})$ during the period March 31 to September 30, 1962.

The most prevalent site for injury was the top of the head in surface workers, and the forehead in underground workers. Normally surface workers do not wear a helmet. Underground workers expose their forehead when they wear their safety helmets in an upwards-tilted position. One reason for this practice is that the helmet has become too small due to shrinkage of the sweatdampened leather headband which occurs after the helmet has been left for some time in the hot pit-head bath lockers.

A helmet which had a wide, unshrinkable, easily adjustable headband made of smooth material was worn by 31 men who had dermatitis or soreness of that part of the skin normally covered by a safety helmet. After six months 26 of these men had no signs or symptoms, confirming that the main cause of helmet dermatitis is friction. A direct relationship between skin rash and sweating was observed in only four of these men.
\end{abstract}

Over the years, the coalminer's safety helmet has prevented many head injuries. It was designed to protect that area of the head above the eyebrows, ears, and occipital protuberance. In front of the helmet there is an attachment on to which an electrical cap lamp can be fixed, and this is often the miner's sole source of illumination at work. A battery attached to the belt which holds up the miner's trousers supplies the current to the cap lamp by way of a cable approximately $4 \mathrm{ft} .2 \mathrm{in}$. $(1.27 \mathrm{~m}$.) long. The cable is fastened to the back of the helmet by a clip, a piece of wire, or string to prevent the cable entangling itself with the miner's arms.

To assess the efficiency of the coalminer's safety helmet, a search was made of the medical centre records at 18 collieries for men who had voluntarily reported, during the period March 31 to September 30,1962 , injuries to that area of the head normally covered by the helmet. Only injuries leaving a visible mark on the skin were included in the survey, i.e., lacerations and bruises. The manpower of these collieries was 16,732 , of whom 13,527 worked underground. Bathing facilities and the services of a State registered nurse were available to all men.

Table 1 divides the head injuries into those occurring at the underground working place, on the underground travelling roads, or on the surface. Head injuries were four times as common at the working place as when travelling underground. One reason for this is that underground men spend ap-

TABLE 1

HEAD INJURIES AND PLACE OF ACCIDENT

\begin{tabular}{l|c|c|c|c}
\hline \multicolumn{1}{c|}{$\begin{array}{c}\text { Place of } \\
\text { Work }\end{array}$} & $\begin{array}{c}\text { No. of Men } \\
\text { Employed }\end{array}$ & $\begin{array}{c}\text { Place of } \\
\text { Accident }\end{array}$ & $\begin{array}{c}\text { No. of Head } \\
\text { Injuries }\end{array}$ & $\begin{array}{c}\text { Rate per Thousand } \\
\text { Men Employed }\end{array}$ \\
\hline Underground & 13,527 & $\begin{array}{l}\text { At working place } \\
\text { On underground travelling roads } \\
\text { All }\end{array}$ & $\begin{array}{c}228 \\
62\end{array}$ & $\begin{array}{c}16.9 \\
4 \cdot 6\end{array}$ \\
\hline Surface & All & 290 & $21 \cdot 4$ \\
\hline All & 3,205 & All & 34 & $10 \cdot 6$ \\
\hline
\end{tabular}


TABLE 2

DISTRIBUTION OF HEAD INJURIES ACCORDING TO PART OF HEAD INJURED AND PLACE OF ACCIDENT

\begin{tabular}{|c|c|c|c|c|c|c|c|}
\hline \multirow{2}{*}{$\begin{array}{l}\text { Place of } \\
\text { Work }\end{array}$} & \multirow{2}{*}{$\begin{array}{l}\text { Place of } \\
\text { Accident }\end{array}$} & \multirow{2}{*}{$\begin{array}{l}\text { Total Head } \\
\text { Injuries }\end{array}$} & \multicolumn{5}{|c|}{ Distribution according to Part of Head Injured (\%) } \\
\hline & & & Front & Top & Side & Back & All \\
\hline Underground & $\begin{array}{l}\text { At working place } \\
\text { On underground travelling roads }\end{array}$ & $\begin{array}{r}228 \\
62\end{array}$ & $\begin{array}{l}60 \\
71\end{array}$ & $\begin{array}{l}16 \\
13\end{array}$ & $\begin{array}{l}17 \\
13\end{array}$ & $\begin{array}{l}8 \\
3\end{array}$ & $\begin{array}{l}100 \\
100\end{array}$ \\
\hline Surface & All & 34 & 24 & 68 & 9 & - & 100 \\
\hline
\end{tabular}

proximately a quarter of their normal working shift travelling to and from their place of work. Surface workers had just about half the rate of head injuries as compared with underground workers.

Table 2 shows the distribution of injuries according to the part of the head injured and the place of accident. The most common site for a surface worker's head injury of the type investigated was the top of the head. Surface men were twice as liable to have this site injured as the men working underground. This is to be expected as helmets are rarely worn by surface men.

The majority of head injuries sustained by men travelling underground or at their underground working place affected the front of the head. This is surprising as most of the forehead is protected by the safety helmet if it is worn correctly. However, many men wear their helmets tilted upwards, exposing part of the forehead. Necessity and not masculine fashion is one reason for this unsafe practice. The inside of the normal coalminer's safety helmet consists of a headband made of leather in various sizes. After an energetic working shift, the leather becomes saturated with sweat. When it is placed in the hot pithead baths locker it shrinks and becomes at least a size smaller by the time it is required for the next work shift. This is particularly true on a Monday after the week-end. Only after a few hours of strenuous underground work does the headband regain its correct size, but by this time the man has accepted the upward-tilted position of the helmet as the usual way of wearing it. Some men immerse their helmets in water at the beginning of each shift to counteract the shrinkage of the headband.

Many safety helmets have a peak in front which protrudes downwards. Any tendency for this peak to enter the upper fields of vision is distracting, and this may be another reason why men wear the helmet tilted upwards.

During the period under review, 30 men reported head rashes to the medical centres; all were caused by wearing a safety helmet. Figure 1 shows a typical helmet headband dermatitis.

Hunt and Watkins (1954) considered that helmet dermatitis was caused by repeated abrasions of the skin from the unhygienic state of the safety helmet headband. They suggested excessive sweating as an additional cause. In 14 out of 22 men whom they investigated, the rash disappeared when a new helmet was used. A further six men had no further head skin trouble when they wore a skull cap of light gauge material. This separated the leather headband from the skin and, if it was changed daily, it also absorbed the sweat. The remaining two cases were only free from the rash when plastic material was substituted for the leather headband of the helmet. One disadvantage of this arrangement was that the plastic material cracks and could become a further cause of skin abrasion. The choice of plastics for use in any headband should be made with care since there are plasticizers which cause dermatitis in sensitive individuals.

The papular non-follicular eruption on that area of the skin exposed to friction by the helmet headband was thought to suggest a sweating aetiology by Hodgson (1955). Friction was said by Edmonds (1956) to be the cause of helmet rash.

The weight of a light-weight safety helmet is $11 \frac{1}{2} \mathrm{oz}$.; the cap lamp weighs $6 \frac{1}{4} \mathrm{oz}$. and the $4 \mathrm{ft}$. 2 in.

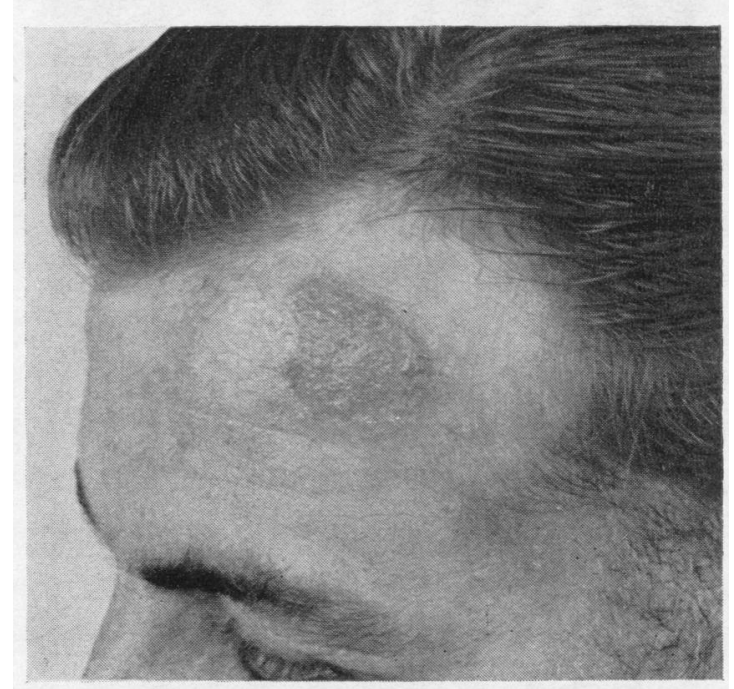

Fig. 1.-A typical case of helmet headband dermatitis. 
$\left(1.27 \mathrm{~m}\right.$.) cable weighs $6 \frac{1}{2} \mathrm{oz}$. The size of a normal miner's safety helmet is determined by the manufacturer. Inside it has a harness with an encircling leather headband. This system cannot be accurately adjusted to fit an individual head size. Unlike other helmets, the miner's safety helmet when worn underground is weighted at the front by a cap lamp. If the helmet is loose, friction occurs to the skin whenever the head is moved. One way of reducing the amount of friction per unit area of the skin is to increase the width of the headband and to use a material that slides on the skin, e.g. plastic, rather than one that clings, e.g. leather. If the headband material does not expand or shrink when saturated with sweat and can easily be adjusted accurately to fit the individual miner's head, then the amount of friction to his head skin will be minimal. A correctly fitting helmet causes the beam of light from the cap lamp to be steady when the miner moves his head. If the cap lamp is the miner's only means of illumination at his working place, then its light efficiency will be decreased if it oscillates when the head moves.

One helmet overcoming some of the disadvantages of the normal miner's helmet is the 'Barbara' type helmet. Figure 2 shows the inside of the helmet

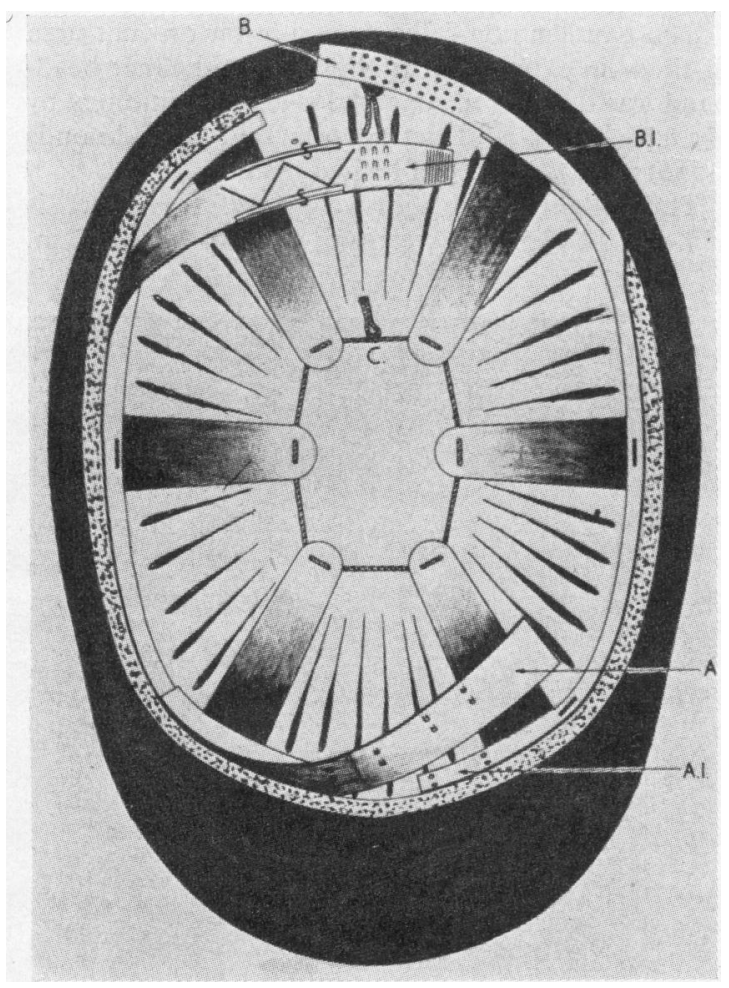

FIG. 2.-A view of the interior of a 'Barbara' safety helmet. which is made of plastic material. The correct size of the helmet is obtained by coarse adjustments at A-A.1 where the plastic prongs of $A$ are pushed into the holes of A.1; fine adjustments can be made at B-B.1 similarly. The plastic band B fits in to the attachment $\mathbf{S}$. The width of the headband is almost $1 \mathrm{in}$. and the headband at the back of the helmet is $1 \mathrm{in}$. lower than at the front. This latter arrangement lessens any tendency for the miner to wear the helmet tilted upwards; if this occurs the headband tends to stick into the back of the neck.

The distance between the dome of the helmet and the top of the head is controlled by the knot C.

Over two years, 31 consecutive men who had helmet complaints were seen by myself. All were given the 'Barbara' type helmet and were seen six months later. They were asked to clean the inside of the plastic headband after each working shift. Twenty of the men had skin rashes on the helmet headband area. Thirteen of these involved only the forehead area, two the forehead and occipital area, and four men had rashes on the side of the head. One man had a rash on the top of the head where the helmet rubbed, as well as on both sides of the head. Seven men had tried wrapping gauze around the leather headband and this had somewhat lessened the skin irritation. A skull cap was worn underneath the helmet by two men. This latter device controlled the skin irritation but tended to make the helmet and therefore the cap lamp unsteady. After wearing the 'Barbara' type helmet for six months, 18 of these men had normal head skin when examined, but the improvement in the forehead skin condition of the other two men was only slight.

A further 10 men complained of soreness of the headband skin area at the end of each shift, and this area was reddened. Only the forehead area was involved in seven men. The forehead and side of the head, the side of the head, and the complete headband area were soreness sites in the other three men. Two of the men found gauze wrapped round the safety helmet headband lessened the soreness. A cloth garter with elastic at each side was worn around the head and under the helmet by one man. He had two of these garters and each was washed after use. This man found that the skin soreness was lessened by this arrangement, and, because of the clinging nature of the garter, the helmet was very stable when the head was moved.

After wearing the 'Barbara' type helmet for six months, seven of these men had no symptoms. One man, who had soreness over a healed laceration, found that after wearing the 'Barbara' type helmet for six weeks his skin had hardened and he could tolerate the ordinary miner's helmet. He preferred 
the latter because the distance between the dome of the helmet and the top of the head was minimal. In a further case soreness of the forehead was much improved and only occurred at the end of the working week. One man had soreness right round the whole helmet headband area; after six months he had only slight soreness at the sides and back of the head.

Irritation by the normal miner's helmet of a bony protuberance behind the left ear occurred in one miner. Because the 'Barbara' type helmet sat higher on the head, this protuberance was not chafed and therefore caused no discomfort.

A direct relationship between skin rash and excessive sweating was only seen in four men.

The 'Barbara' type helmet is ventilated through four small holes, two at the side of the helmet and two at the back. Air cannot get round the sides of the helmet because of sponge rubber between the headband and the helmet. There is a gap of $1 \frac{3}{4}$ in. in the sponge rubber in front of the helmet and approximately 4 in. at the back. Ten men felt they sweated more in this helmet; five of these had had a helmet dermatitis which had cleared, and two still had a rash. Three men had had skin soreness around the headband area, but two of these had no symptoms after wearing the 'Barbara' type helmet for six months.

\section{Discussion}

The safety helmet houses the miner's cap lamp, and this light is often the miner's sole source of illumination. The position of the helmet on the miner's head controls the direction of the cap lamp's beam of light, which can only be changed by moving the head or altering the position of the helmet. One device which allows speedy adjustment in the vertical axis of the beam by the miner without moving his head or altering the position of the helmet is the John T. Moss adjustable cap lamp bracket (T. A. Hunt, personal communication).

The miner's safety helmet must be made of materials which are light in weight and strong enough to give adequate protection to the head, and its purchase price must be reasonable. If it fits a miner's head loosely, it will cause the cap lamp to oscillate whenever he moves the head. The headband harness material must remain constant in size when exposed to sweat or heat. If the helmet is too small, men will wear it tilted upwards and the forehead will be exposed. Therefore it is important that the helmet head harness should have a wide, easily adjustable headband so that the helmet always fits the miner's head accurately. The peak of the helmet must not be seen in the wearer's field of vision.

The inside of the helmet must be adequately ventilated, and the distance between the top of the head and the dome of the helmet should be minimal.

If helmets are designed according to these principles, worn correctly, and adequately maintained, then the number of head injuries will be diminished. The incidence of helmet dermatitis will also be lessened. This is shown by the fact that 26 out of 31 men who had dermatitis or soreness of that area of the skin normally pressed on by the safety helmet had no signs or symptoms after six months of constantly wearing the 'Barbara' type helmet, which is designed according to some of these principles.

I am very grateful to Mr. J. Wright, Area Production Manager, and Mr. F. G. Vernon, Area Safety Engineer, of the No. 4 Area, East Midlands Division, National Coal Board, who initially asked me to investigate the medical problems of wearing the 'Barbara' type helmet. To the East Midlands Divisional Medical Officer, Dr. J. T. Watkins, and my colleague, Dr. T. A. Hunt, thanks are given for their keen interest. I am grateful to Mr. D. F. K. Liddell of the Headquarters Medical Service of the National Coal Board for his help on the statistical aspects of this paper. Special thanks are also given to Mr. D. A. Brown, Area Photographer, for Fig. 1, and to Mr. C. Skeavingtori, No. 4 Group Surveyor, and J. Clifford, Assistant Surveyor, Teversal Colliery, for Fig. 2, all of the No. 4 Area, East Midlands Division, National Coal Board.

\section{REFERENCES}

Edmonds, O. P. (1956). Trans. Ass. industr. med. Offrs., 6, 50, Hodgson, G. (1955). Brit. J. Derm., 67, 426. Hunt, T. A., and Watkins, J. T. (1954). Colliery Engng., 31, 418. 